\title{
NOTES
}

or $A$

\section{CASE OF HYDROPHOBIA,}

\author{
WITR
}

SOME REMARKS ON THE PATHOLOGY OF THAT DISEASE.

BY GEORGE GREGORY, M.D.

SECRETARY TO THE MEDICAL AND CHIRURGICAL SOCIETY, PHYSICLAN TO THE sMaLI-rox hOsPrial, ETC.

Read June 28, 1825.

GEORGE Sandall, twenty-eight years of age, the servant of Haviland Addington, Esq., was the subject of the following case. He was of a remarkably strong, athletic habit of body, broadchested, and full-blooded. He had been troubled occasionally with rheumatism, and about a twelvemonth prior to the date of that attack to which I am about to call the attention of the Society, he had suffered from rheumatism in an acute form. His habits were active, and his disposition lively.

Very early in the month of May last, (probably either Monday the $2 \mathrm{~d}$ or Tuesday the $3 \mathrm{~d}$ ), he was enjoying himself with some fellow-servants at the public-house called the Queen's Head, in Stafford Street, Albemarle Street, when his attention was 
caught by a stray terrier dog lying under the table. In rude play, he seized the dog by the tail, who turned round and bit him in the outer side of the left hand*. He complained a good deal of the hand that evening and the following day. Soon after this, it was noticed by several of his friends that his spirits flagged; he became dull and melancholy, but when pressed to explain the cause of this oppression upon his spirits, he made light of it, and tried to laugh it off. Once or twice however he appears to have alluded to his hand, which he said was affected with rheumatism. Frequently during the same period he complained of severe rheumatic pain and swelling of the knee, which he bathed continually with warm water, intimating to several of his acquaintances that he feared he was going to be laid up with an attack of his old enemy, the rheumatism.

About Friday, June 10th (thirty-nine days, as nearly as can be ascertained, from the infliction of the wound), he began to complain of soreness of his throat. He could not swallow without inconvenience, and this increased considerably upon the Saturday. On both of these days his left hand, he said, felt queer, and he noticed a slight puffiness upon the back of it, which he attributed to rheumatism.

* All my endeavours to trace out the further history of the dog proved ineffectual. 
On Sunday he dined with the family, and ate heartily. He still however continued to complain of his throat, and of a difficulty in swallowing; but he nevertheless took two pints of porter at his meal. On returning home from his walk that afternoon (Sunday, June 12th), he complained that the wind in the hall-passage affected him, and he nearly fell down. Several times during the course of this evening a sense of suffocation came over him, and he swallowed his tea with considerable pain. He appears to have passed a restless night, and on Monday morning he complained of being so weak and poorly as to be unable to clean his master's shoes.

Some of his friends who met him that morning noticed a staggering in his walk, and an expression of countenance as if he had been intoxicated the preceding evening; nor were they without difficulty persuaded of the contrary. Several times in the course of Monday he was sick at stomach, and on this day he applied to Mr. Smith, a stablekeeper in Mason's Yard, Maddox Street (where his master's horses were kept), for a prescription for the rheumatism, of whose virtues he had heard. This composition, consisting chiefly of sulphur and gum guaiacum, was given to him, and he then returned home. About four o'clock that afternoon the symptoms assumed a more decided character. An hysterical catching of the breath now came 
on, and deglutition became more and more painful. He succeeded however in getting down two cups of tea.

During the early part of the night he was excessively restless, complaining of the least breath of air. About two o'clock, he asked for some water to drink; when it was brought to him, he threw himself to the other side of the bed with a sort of convulsive agitation, which the person in attendance not inaptly compared to the sudden spring of a flounder.

An antispasmodic julep was procured from a neighbouring chemist's shop, which, however, he could not be prevailed upon to take, expressing at the same time his readiness to try some medicine that was thick. This expression first opened the eyes of those around him to the real nature of his disorder.

At eight o'clock on Tuesday morning (June 14th), he was visited by Dr. Wilson Philip, who found him in a highly nervous and irritable condition. His breathing was in short catches, attended with that noise commonly observed after plunging into cold water. His pulse was but little affected. He made no particular complaints, but his manner was hurried, and his eye wandered from the door to the window in a very characteristic manner. He attempted to swallow a pill which Dr. Philip voL. XIII. 
prescribed, but it is doubtful whether he succeeded. At eleven o'clock he was, by Dr. Philip's advice, put into the warm bath, which he bore with firmness, and without complaint ; but immediately on coming out of it, the symptoms increased with alarming violence, and with a rapidity almost unequalled in the records of this terrible malady. He was again visited by Dr. Philip between twelve and one, and by Dr. Hooper at two. He made an attempt to swallow liquids in Dr. Hooper's presence. A teapot was brought to him covered, in order that the sight of the water might not operate prejudicially. This he seized with both hands, and, after waiting a few seconds in great agitation, threw it up convulsively to his mouth, and succeeded in swallowing a portion.

Sickness at stomach now supervened, and, when I saw him for the first time (which was at three o'clock), he was bringing up phlegm, although with great and painful efforts. He had thrown off all the bed-clothes, and was continually shifting his position in the bed in extreme agitation. The least breath of air made him shiver, and seemed to give him excessive uneasiness. His skin was cool; his pulse fluttering and indistinct. At times he spoke calmly, and appeared anxious to restrain (as far as he possibly could) the mental and bodily agitation under which he laboured. Leaving him for a time in the care of Mr. Alcock, I went to St. George's Hospital to make arrangements for 
his reception there, in conformity to the suggestion of Dr. Hooper, as well as my own and his master's wishes.

On my return, I found him still excessively sick at stomach, and learned that he had brought up a little blood. He walked, with some help, down stairs, and was put into a coach. During the journey he was again attacked with sickness at stomach, and his efforts at vomiting were dreadful. He brought off phlegm, blood, and some matter having the appearance of coffee grounds. Just as the coach reached the door of the hospital, he fell into a convulsion-fit, which put a period to his sufferings and his life in less than ten minutes after being received into the ward.

\section{Dissection.}

The body was opened the following day (Wednesday, June 15), under the direction of Dr. Hewett, in the presence of Dr. Philip and a large concourse of professional gentlemen. The following were the appearances which presented themselves.

The spinal marrow throughout its whole extent was perfectly free of disease. There was some slight effusion of serum on the surface of the brain, and about three or four tea-spoonfuls of serum were contained within the ventricles. The 
260 DR. GREGORY's CASE OF HYDROPHOBIA.

choroid plexus was turgid with blood, and two very small soft tumors were found attached to it.

The stomach and bowels were in a healthy state. The lungs were of a remarkably dark colour, as if gorged with venous blood". The whole body, it may be noticed, had become livid with remarkable rapidity, and to a very uncommon extent.

The pharynx, epiglottis, and larynx - the œsophagus, for about the first three inches of its course -and the trachea, throughout its whole extent, appeared internally of a coffee-ground colour, or almost black. This blackness remained after the parts had been freely sponged. There was no thickening or swelling of the parts about the glottis. The structures were firm, nor could I detect any breach of surface in the affected membrane. I have since been informed, however, that an abrasion of the cuticular lining of the membrane was noticed about half an inch below the pharynx.

The inner coat of the aorta, and large arteries immediately proceeding from it was of a bright scarlet colour. The heart and pericardium were healthy.

The First Volume of the Transactions of this Society contains a most interesting account of a

* A gentleman present considered that the lungs were, in some parts, emphysematous. 
case of hydrophobia by the late Dr. Marcet. The author there* states, as an apology for the details into which he enters, " that it is only by multiplying observations, and by diligently collecting descriptions of the disease, that we can hope to throw some light on its nature." A similar feeling induces me to submit this case to the notice of the Society, and to offer the following cursory reflections upon the pathology of this remarkable disorder.

Fully sensible as I am that a high degree of nervous irritation is the predominant feature of the symptoms during life, and that the appearances which present themselves after death (as hitherto observed) possess no common character, yet it is impossible, I think, in any reasonings concerning this particular case, to avoid associating together the sore-throat which characterized its early period, the dread of water which indicated its confirmed stage, and the peculiar appearances about tise throat, which were demonstrated upon dissection. These phenomena tend to the conclusion that the symptom which gives name to the disease is di. rectly dependent upon some form of inflammatory action in the larynx and pharynx, and that the true nosological situation of hydrophobia is in the genus cynanche. If such a view of the pathology of the disease should be confirmed. by further observation, it would be a singular instance of 
262 DR. GREGORY'S CASE OF HYDROPHOBIA.

fortuitous nomenclature. To no other variety of inflammation about the throat could the term cynanche be so appropriately applied.

That many objections may be taken to this doctrine, I am well aware. Such appearances about the throat as were witnessed in this case are far from being uniformly met with, even where the dread of water was most strongly marked, but it happens that in the only other case of hydrophobia which fell under my own observation (that of a stable boy treated by Dr. Chambers at St. George's Hospital in December, 1816), they were equally distinct; and, in Dr. Marcet's case, just referred to, the same thing occurred. "The pharynx", it is stated", "was considerably inflamed, behind both the mouth and nose, and in the œsophagus there were several detached spots of inflammation at various distances in the course of its canal."

My object, in pressing the consideration of this subject, is to afford, if possible, some principle by which our treatment in future cases of hydrophobia may be regulated. It may be worth mentioning (though more as a matter of curiosity than of real importance), that four leeches were, in Dr. Marcet's case, applied to the throat, which bled freely, "to which circumstance the patient attributed his apparent improvement" + . There

* Medico-Chirurgical Transactions, Vol. I. p. 154.

† Ib. page 140. 
can be no doubt that when the characteristic features of the disease are fully developed, no remedial measures are likely to be of any avail ; but it is an important consideration that in almost all cases there is a premonitory period (generally lasting two or three days, but sometimes extending to five or even six), during which it is still possible that something may be done. In the case now detailed, it appears to have commenced on the Friday, and to have lasted till Sunday night. I am not aware that any measures have ever been tried at this period of the disease to avert the impending danger, but this may have arisen, sometimes from ignorance of the real nature of the disease, and as often perhaps from an unwillingness to admit it. I would venture to suggest, therefore, that, when a man has been bitten by a rabid animal, he should be closely watched about the end of the fourth week; and, on the first appearance of any marks of nervous irritation or uneasiness about the throat, those remedies should be adopted, of whatever kind, which the practitioner would hàve employed, had the real nature of the disease been unequivocally ascertained.

8, Upper John Street, Golden Square,

June 25, 1825. 